ment: the jaundice diminished, and bile reappeared in considerable quantity in the motions. But about Nov. 12th the vomiting became more urgent, and the prostration increased. On Nov. 19th the left foot was found to be much swollen, and livid lines marking the course of the lymphatics passed up the legs. On Nov. 20th, an abscess was opened above the left ankle, from which fetid pus and gas escaped. On the same day he was seized with a fit of convulsions, followed by coma. These fits recurred in rapid succession, so that he had nearly thirty before his death at five P.M. on Nov. 21 st.

On examination of the body after death, the brain and its membranes were found to be normal, except that there was a considerable amount of fluid, which contained urea, at the base and in the lateral ventricles. The kidneys were considerably enlarged, and there was much fatty and granular deposit in the secreting cells. The liver was large, and weighed $80 \mathrm{oz}$. its secreting cells were loaded with oil ; the lobules were unusually distinct, giving a granular appearance to the organ on section. The gall-bladder contained a soft, black concretion, as large as a walnut, and many small, irregularly-shaped frag ments of the same material. These were suspended in a small quantity of dark-green viscid fluid, which, on microscopic exarination, was found to contain a large number of pus-corpuscles. The mucous surface of the gall-bladder had a stretched, white appearance, and at the fundus was deeply injected, granular, and excoriated. The bile-ducts contained a similar viscid fluid to that in the gall-bladder, with minute particles of black inspissated bile. This could be squeezed into the duodenum without much difficulty. The mucous membrane of the stomach and duodenum was minutely injected with numerous small echymoses, and the surface was coated with much viscid mucus. There was great œdema and congestion of both lungs. Fat was deposited in large quantity throughout the body, and all the soft tissues were deeply jaundiced.

The examination made it clear that the fatal result was due to uræmia, while it also showed that the hepatic symptoms were probably the result of catarrh of the gall-bladder and bile-ducts, excited by the gall-stones, but which was subsiding before death.

In the case from which this preparation was obtained, there was painful enlargement of the gall-bladder and jaundice, arising from obstruction of the duct caused by cicatrisation of a duodenal ulcer.

CASE 4.-James B_, aged sixty-nine, a coachman, was admitted, nnder Dr. Stewart, on May 4th, 1861. With the exception of a similar but less severe attack some years before, he had enjoyed good health until four months before admission, when he had been suddenly seized with acute pain in the right hypochondrium, vomiting of bitter matter, and much fever. After a few days his skin became jaundiced, and he had great formication. The jaundice increased in intensity, but the formication diminished. Latterly he had suffered from palpitation in the cardiac region and throbbing in the head, and he had lost both flesh and strength.

On admission, the patient was emaciated and feeble; the pulse was 72, and intermitting; the whole skin and the conjunctivæ were bright yellow. The patient complained of a dull pain in the region of the liver, the dulness on percussion - of which appeared considerably increased, measuring upwards of five inches in the right mammary line. On more careful examination, it was ascertained that this enlargement was limited to the situation of the gall-bladder, and that posteriorly and laterally the hepatic dulness was diminished. The patient was treated with alkalies, ammonia, vegetable bitters, and stimulants; but his prostration rapidly increased, and on May 19 th he died from exhaustion.

At the autopsy, the liver was found to be small, pale, and flabby. Its lower margin did not reach so far as the edge of the ribs. The gall-bladder was about four times the normal size, and was filled with a colourless, flaky fluid, destitute of any tint of bile. The cystic, hepatic, and common ducts were all enormously dilated, the common duct being larger than one's finger, and all were filled with a colourless fluid, similar to that in the gall-bladder. The bile-ducts also in the interior of the liver were greatly dilated as far even as the outer surface, and filled with a similar fluid, which flowed out when the liver was cut into. There was no calculus in the gallbladder or in any of the ducts, but the orifice of the common duct in the duodenum was completely blocked up. The mucous membrane at this part was considerably thickened, forming a nipple-like prominence about the size of a hazel-nut, and aroun this the membrane had a radiated, puckered appearance, as if from the cicatrisation of an ulcer. There was much atheroma of the aorta and of the valves of the heart. The prostate was enlarged, the bladder inflamed, and the kidneys were grannlar, with dilatation of the pelves and calices.

The contraction of the liver in this case was, no doubt, due to the long duration of the obstruction, the hepatic tissue having become atrophied from the pressure of the permanently distended bile-ducts.

\section{ON THE ANTISEPTIC PRINCIPLE IN THE PRACTICE OF SURGERY.*}

BY JOSEPH LISTER, Esq., F.R.S., PROFESSOR OF SURGERT IN THE UNIVERSITY OF GLASGOW.

IN the course of an extended investigation into the nature of inflammation, and the healthy and morbid conditions of the blood in relation to it, I arrived, several years ago, at the conclusion that the essential cause of suppuration in wounds is decomposition, brought about by the influence of the atmosphere upon blood or serum retained within them, and, in the case of contused wounds, upon portions of tissue destroyed by the violence of the injury.

To prevent the occurrence of suppuration, with all its attendant risks, was an object manifestly desirable; but till lately apparently unattainable, since it seemed hopeless to attempt to exclude the oxygen, which was universally regarded as the agent by which putrefaction was effected. But when it had been shown by the researches of Pasteur that the septic property of the atmosphere depended, not on the oxygen or any gaseous constituent, but on minute organisms suspended in it, which owed their energy to their vitality, it occurred to me that decomposition in the injured part might be avoided without excluding the air, by applying as a dressing some material capable of destroying the life of the floating particles.

Upon this principle $I$ have based a practice of which I will now attempt to give a short account.

The material which I have employed is carbolic or phenic acid, a volatile organic compound which appears to exercise a peculiarly destructive influence upon low forms of life, and hence is the most powerful antiseptic with which we are at present acquainted.

The first class of cases to which I applied it was that of compound fractures, in which the effects of decomposition in the injured part were especially striking and pernicious. The results have been such as to establish conclusively the great principle, that all the local inflammatory mischief and general febrile disturbance which follow severe injuries are due to the irritating and poisoning influence of decomposing blood or sloughs. For these evils are entirely avoided by the antiseptic treatment, so that limbs which otherwise would be un hesitatingly condemned to amputation may be retained with confidence of the best results.

In conducting the treatment, the first object must be the destruction of any septic germs which may have been introduced into the wound, either at the moment of the accident or during the time which has since elapsed. This is done by introducing the acid of full strength into all accessible recesses of the wound by means of a piece of rag held in dressing forceps and dipped in the liquid. + This I did not venture to do in the earlier cases; but experience has shown that the compound which carbolic acid forms with the blood, and also any portions of tissue killed by its caustic action, including even parts of the bone, are disposed of by absorption and organisation, provided they are afterwards kept from decomposing. We are thus enabled to employ the antiseptic treatment efficiently at a period after the occurrence of the injury at which it would otherwise probably fail. Thus I have now under my care in the Glasgow Infirmary a boy who was admitted with compound fracture of the leg as late as eight and a half hours after the accident, in whom nevertheless all local and constitutional disturbance was avoided by means of carbolic acid, and the bones were firmly united five weeks after his admis. sion.

The next object to be kept in view is to guard effectually against the spreading of decomposition into the wound along

* A paper read before the British Medical Association in Dublin on the 9 th of August, 1867.

$t$ The addition of a few drops of water to a conciderable quantity of the eryetallised acid induces it to assume permanently the liquid form. 
the stream of blood and serum which oozes out during the first fow days after the accident, when the acid originally applied has been washed out, or dissipated by absorption and evajoration. This part of the treatment has been greatly improved during the last few weeks. The method which I have hitherto published ${ }^{*}$ consisted in the application of a piece of lint dipped in the acid, overlapping the sound skin to some extent, and covered with a tin cap, which was daily raised in order to touch the surface of the lint with the antiseptic. This method certainly'succeeded well with wounds of 'moderate size; and, indeed, I mayisay that in all the many cases of this kind which have been so treated by myself or my house-surgeons, not a single failure has occurred. When, however, the wound is very large, the flow of blood and serum is so profuse, especially during the first twenty-four hours, that the antiseptic application cannot prevent the spread of decomposition into the interior unless it overlaps the sound skin for a very consideralule distance, and this was inadmissible-by the methot described above, on account of the extentsive sloughing of the surface of the cutis which it would involve. This difficulty has, however, been overcome -by employing a paste composed of common whitening (carbonate of lime) mixed with a solution of ore part of carbolic acid in four parts of boiled linseed oil, so as to form a firm putty. This application contains the acid in too dilute a form to excoriate the skin, which it may be made to cover to any extent that may be thought desirable, while its sabstanee serves as a reservoir of the antiseptic material. So long as any discharge continues, the paste should be changed daily; and, in order to prevent the chance of mischief occurring during the ${ }^{t}$ process, a piece of rag dipped in the solution of carbolic acid in oil is put on next the skin, and maintained there perrmanently, care being taken to avoid raising it along with the putty. This rag is always kept in an antiseptic condition from contact with the paste above it, and destroys any germs that may fall upon it during the short time that should alotie be allowed to pass in the changing of the dressing. The prtty should be in a lajer about a quarter of an inch thick; and may be advantageously applied rolled out between two pieces of thin calico, which maintain it in the form of a continuous sheet, that may be wrapped in a moment round the whole "circumference of "a limb, if this be thought desirable, while the putty is prevented by the calico from sticking to the ra' which is next the skin. $t^{\prime}$. When all discharge has ceased, the use of the paste is discontinued, but the original rag is left adhering to the skin till thealing by scabbing is supposed to be complete. I have at present in the hospital a man with severe cormpound fracture of both bones of the left leg, caused by direct violence, who, after the cessation of the sanious disoharge under the use of the paste, without a drop of pus appearing, has been treated for the last two weeks exactly as if the fracture were a simple one. During this time the rag, adhering by means of a crust of inspissated blood collected beneath it, has continued perfectly dry, and it will be left untouoned till the usual period for removing the splints in a simple fracture, when we may fátrly expect to find a sound cioatrix beneath it

We cannot, how̌ver, alwáys ealculate on so perfect a résult as this. More or less pus may sponer after the lapse of the first week; and the larger the wotnd the more likely is this to ${ }^{2}$ happen. And here I would dessire earnestly to enforce the necessity of persevering with the antiseptic application, in spite of the appearance of suppuration, solong as other'symptoms are favourable. The surgeon is extremely apt to suppose that any suppuration is an indieation that the antiseptic treatment has failed, and that poulticing or water-dressing should be resorted to. But such a course would in many cosses 'sacrifice a limb or a life. I cannot, however, expect my professional brethren to follow my advice blindly in steh a matter, and therefore I feel it necessary to place before them, as shortly as [ can, some pathological principles, intimately connected not only with the point we are immediately considering, but with the whole subject of this paper.

If a perfectly healthy granulating sore be well washed and covered with a plate of clean metal, such as block tin, fitting its surface pretty accurately, and overlapping the surrounding skin an inch or so in every direction, and retained in position by adhesive plaster and a bandage, it will be found, on removing it after twenty-four or forty-eight hours, that little or

* See The Lavert for Mareh 16th, 23rd, and 30th, and April 27th, of the prosent year.

t It order to prevent evaporation of the acid; which passes readily throngh any organie tissue, such as oiled silk or gutta percha, it is well to cover the paste with a sheet of block tin, or tinfoil strengthened with adhesive plaster. The thin sheet-lead used for lining tea-chesis will ralso answer the purpose, and may be obtained from any wholesale grocer. nothing that can be called pus is present, merely a little trans parent fluid, while at the same time there is an entire absence of the unpleasant odour invariably perceived when waterdressing is changed. Here the clean metallic surface presenting no recesses, like those of porous lint, for the septic gerins to develop in, the fluid exuding from the surface of the granulations has flowed away undecomposed, and the result is absence of suppuration. This simple experiment illustrates the important fact, that granulations have no inherent tendency to form pus, but do so only when subjected to a preternatural stimulus. Further, it shows that the mere contact of a foreign body does not of itself stimulate granulations to suppurate; whereas the presence of decomposing organic matter does. These truths are even more strukingly exemplified by the fact, which I have elsewhere recorded, * that a piece of dead bone, free from decomposition, may not only fail to in. duce the granulations around it to suppurate, but may actually be absorbed by them; whereas a bit of dead bone soaked with putrid pus infallibly induces suppuration in its vicinity.

Another instructive experiment is to dress a granulating sore with some of the putty above described, overlapping the sound skin extensively, when we find in the course of twenty-four hours that pus has been produced by the sore, although the application has been perfectly antiseptic; and, indeed, the larger the amount of carbolic aeid in the paste the greater is the quantity of pus formed, provided we avoid such a proportion as would act as a caustic. The carbolic acid, though it prevents decomposition, induces - suppuration - obviously by acting as a chemical stimulus; and we may safely infer that putrescent organic materials (which we know to be chemically acrid) operate in the same way.

In so far, then, carbolic acid and decomposing substances are alike-namely, that they induce suppuration by chemical stimulation, as distinguished from what may be termed simple inflammatory suppuration, such as that in which ordinary abscesses originate, where the pus appears to be formed in consequence of an excited aetion of the nerves, independently of any other stimulus. There is, however, this enormous differenee-between the effects of carbolic acid and those of decomposition-viz., that carbolic acid stimulates only the surface to which it is first applied, and every drop of discharge that forms:-weakens the stimulant by diluting it. But decomposition is'a self-propagating and self-aggravating poison ; and if it occurs at the surface of a severely injured limb, it 'will spread into all its recesses so far as any extravasated blood or shreds of deaid tissue may extend, and, lying in these recesses, it will become from hour to hour more acrid till it acquires the energy of a caustic, sufficient to destroy the vitality of any tissues naturally weak from inferior vascular supply, or weakened by the injury they sustained in the accident.

Hence it is easy to understand how, when a wound is very large, the erust beneath the 'rag may prove here and there insufficient to protect the raw'surface from the stimulating infliuence of the carbolic acid in the putty, and the result will be, first, the conversion of the tissues so acted on into granula tions, and subseouently the formation of more or less pus. This, however, will be merely superficial, and will not interfere with the absorption and organisation of extravasated blood or dead tissues in the interior; but, on the other hand, shoulu decomposition set in before the internal parts have become fecurely consolidated, the-most disastrous: results may ensue.

I left behind me in Glasgow a boy, thirteen years of-age; who between three and four weeks previously met with a most severe injury to the left arm, which he-got enta"gled in a machine at a fair. There was a wound six inches long and three inches broad, and the skin was very extensively undermined beyond its limits, while the soft parts generally were'so much lacerated that a pair of dressing forceps introdaced at the wound, and pushed direetly inwards, appeared beneath the skin at the opposite aspect of the limb. From this wound several tags of muscle were hanging, and among them there was one consisting of about three inches of the triceps in almost its entire thickness; while the lower fragment of the bone, which was broken high up, was protruding four and a half inches, stripped of muscle, the skin being tucked in under it. Withou't the assistance of the antiseptic treatment, I shonld certainly have thought of nothing else but amputation at the shoulder-joint; but as the radial pulse could be felt, and the fingers had sensation, I did not hesitate to try to save the $\operatorname{limb}$, and adopted the plan of treatment above described, wrapping the arm from the shoulder to below the elbow in the antiseptic application, the whole interior of the wound, together with the protruding bone, having previously been freely treated * See Thr Laycer, Maroh 23rd, 1867. 
with strong carbolic acid. About the tenth day the discharge, which up to that time had been only sanious and serous, showed a slight admixture of slimy pus, and this increased till, a few days before I left, it amounted to about three drachms in twenty-four hours. But the boy continued, as he had been after the second day, free from unfavourable symptoms, with pulse, tongue, appetite, and sleep natural, and strength increasing, while the limb remained, as it had been from the first, free from swelling, redness, or pain. I therefore persevered with the antiseptic dressing, and before I left, the discharge was already somewhat less, while the bone was becoming firm. I think it likely that in that boy's case I should have found merely a superficial sore had I taken off all the dressings at the end of three weeks, though, considering the extent of the injury, I thought it prudent to let the month expire before disturbing the rag next the skin. But I feel sure that if $I$ had resurted to ordinary dressing when the pus first appeared, the progress of the case would have been exceedingly different.

The next class of cases to which I have applied the antiseptic treatment is that of abscesses. Here, also, the results have been extremely satisfactory, and in beautiful harmony with the pathological principles indicated above. The pyogenic membrane, like the granulations of a sore, which it resembles in nature, forms pus, not from any inherent disposition to do so, but only because it is subjected to some preternatural stimulation. In an ordinary abscess, whether acute or chronic, before it is opened, the stimulus which maintains the suppuration is derived from the presence of the pus pent up within the cavity. When a free opening is made in the ordinary way, this stimulus is got rid of ; but the atmosphere gaining access to the contents, the potent stimulus of decomposition comes into operation, and pus is generated in greater abundance than before. But when the evacuation is effected on the antiseptic principle, the pyogenic membrane, freed from the influence of the former stimulus witbout the substitution of a new one, ceases to suppurate (like the granulations of a sore under metallic dressing), furnishing merely a trifling amount of clear serum, and, whether the opening be dependent or not, rapidly contracts and coalesces. At the same time any constitutional symptoms previously occasioned by the accumulation of the matter are got rid of without the slightest risk of the irritative fever or hectic hitherto so justly dreaded in dealing with large abscesses.

In order that the treatment may be satisfactory, the abscess must be seen before it has opened. Then, except in very rare and peculiar cases,, there are no septic organisms in the contents, so that it is needless to introduce carbolic acid into the interior. Indeed, such a proceeding would be objectionable, as it would stimulate the pyogenic membrane to unnecessary suppuration. All that is necessary is to guard against the introduction of living atmospheric germs from without, at the same time that free opportunity is afforded for the escape of discharge from within.

I have so lately given elsewheret a detailed account of the method by which this is effected, that it is needless for me to enter into it at present, further than to say that the means employed are the same as those described above for the superficial dressing of compound fractures-namely, a piece of rag dipped in the solution of earbolic acid in oil, to serve as an antiseptic curtain, under eover of which the abscess is evacuated by free incision; and the antiseptic paste, to guard against decomposition occurring in the stream of pus that flows out beneath it: the dressing being changed daily till the sinus has closed.

The most remarkable results of this practice in a pathological point of view have been afforded by cases where the formation of pus depended upon disease of bone. Here the abscesses, instead of forming exceptions to the general class in the obstinacy of the suppuration, have resembled the rest in yielding in a few days only a trifling discharge; and frequently the production of pus has ceased from the moment of the evacuation of the original contents. Hence it appears that caries, when no. longer labouring, as heretofore, under the irritation of decomposing matter, ceases to be an opprobrium of surgery, and recovers like other inflammatory affections. In the publication before alluded to $\neq$ I have mentioned the case of a middle-aged man with psoas abscess depending on diseased bone, in whom the sinus finally closed after months of patient perseverance with the antiseptic treatment. Since that article

* As an instance of one of these exceptional cases, I may mention that of an abscess in the vicinity of the colnn, and afterwards proved by post-mortem examination to have once communicated with it. Here the pus was extremely offensive when evackated, and exhibited vibrios under the micro. scope.

t See THE LAXrcet of Joly 27 th, 1867. $\ddagger$ Ibid. was written I have had another instance of success, equally gratifying, but differing in the circumstance that the disease and the recovery were both more rapid in their course. The patient was a blacksmith who had suffered four and a half months before I saw him from symptoms of ulceration of cartilage in the left elbow. These had latterly increased in severity, so as to deprive him entirely of his night's rest and of appetite. I found the region of the elbow greatly swollen, and on careful examination discovered a fiuctuating point at the outer aspect of the articulation. I opened it on the antiseptic principle, the incision evidently penetrating to the joint, giving exit to a few drachms of pus. The medical gentleman under whose care he was (Dr. Macgregor of Glasgow) supervised the daily dressing with the carbolic-aid paste till the patient went to spend two or three weeks at the coast, when his wife was entrusted with it. Just two months after I opened the abscess he called to show me the limb, stating that the discharge had for at least two weeks been as little as it then was-a triffing moisture upon the paste, such as might be accounted for by the little sore caused by the incision. On applying a probe guarded with an antiseptic rag, I found that the sinus was soundly closed, while the limb was free from swelling or tenderness; and, although he had not attempted to exercise it much, the joint could already be moved through a considerable angle. Here the antiseptic principle had effected the restoration of a joint which on any other known system of treatment must have been excised.

Ordinary contused wounds are of course amenable to the same treatment as compound fractures, which are a complicated variety of them. I will content myself with mentioning a single instance of this class of cases. In April last a volunteer was discharging a rifle, when it burst, and blew back the thumb with its metacarpal bone, so that it could be bent back as on a hinge at the trapezial joint, which had evidently been opened, while all the soft parts between the metacarpal bones of the thumb and forefinger were torn through. I need not insist before my present audience on the ugly character of such an injury. My house-surgeon, Mr. Hector Cameron, applied carbolic acid to the whole raw surface, and completed the dressing as if for compound fracture. The hand remained free from pain, redness, or swelling, and, with the exception of a shallow groove, all the wound consolidated without a drop of matter, so that if it had been a clean cut, it would have been regarded as a good example of primary union. The small granulating surface soon healed, and at present a linear cicatrix alone tells of the injury be had sustained, while his thumb has all its movements and his hand a firm grasp.

If the severest forms of contused and lacerated wounds heal thus kindly under the antiseptic treatment, it is obvious that its application to simple incised wounds must be merely a matter of detail. I have devoted a good deal of attention to this class, but I have not as yet pleased myself altogether with any of the methods I have employed. I am, however, prepared to go so far as to say that a solution of carbolic acid in twenty parts of water, while a mild and cleanly application, may be relied on for destroying any septic germs that may fall upon the wound during the performance of an operation; and also that for preventing the subsequent introduction of others, the paste above described, applied as for compound fractures, gives excellent results. Thus I have had a case of strangulated inguinal hernia, in which it was necessary to take away half a pound of thickened omentum, heal without any deep-seated suppuration or any tenderness of the sac or any fever; and amputations, including one immediately below the knee, have remained absolutely free from constitutional symptoms.

Further, I have found that when the antiseptic treatment is efficiently conducted, ligatures may be safely cut short and left to be disposed of by absorption or otherwise. Should this particular branch of the subject yield all that it promises, should it turn out on further trial that when the knot is applied on the antiseptic principle, we may calculate as securely as if it were absent on the occurrence of healing without any deep-seated suppuration; the deligation of main arteries in their continuity will be deprived of the two dangers that now attend it-viz,, those of secondary hæmorrhage and an unhealthy state of the wound. Further, it seems not unlikely that the present objection to tying an artery in the immediate vicinity of a large branch may be done away with; and that even the innominate, which has lately been the subject of an ingenious experiment by one of the Dublin surgeons on account of its well-known fatality under the ligature from secondary hæmorrhage, may cease to have this unhappy character, when the tissues in the vicinity of the thread, instead of becoming softened through the influence of an irritating decomposing 
substance, are left at liberty to consolidate firmly near an unoffending though foreign body.

It would carry me far beyond the limited time which, by the rules of the Association, is slone at my disposal, were I to enter into the various applications of the antiseptic principle in the several special departments of surgery.

There is, however, one point more that $I$ cannot but advert to-namely, the influence of this mode of treatment upon the general healthiness of an hospital. Previously to its introduction, the two large wards in which most of my cases of accident and of operation are treated were amongst the unhealthiest in the whole surgical division of the Glasgow Royal Infirmary, in consequence, apparently, of those wards being unfavourably placed with reference to the supply of fresh air; and I have felt ashamed, when recording the results of my practice, to have so often to allude to hospital gangrene or pyrmia. It was interesting, though melancholy, to observe that, whenever all, or nearly all, the beds contained cases with open sores, these grievous complications were pretty sure to show themselves; so that I came to welcome simple fractures, though in themselves of little interest either for myself or the students, because their presence diminished the proportion of open sores among the patients. But since the antiseptic treatment has been brought into full operation, and wounds and abscesses no longer poison the atmosphere with putrid exhalations, my wards, though in other respects under precisely the same circumstances as before, have completely changed their character; so that during the last nine montius not a single instance of pyæmia, hospital gangrene, or erysipelas has occurred in them. As there appears to be no doubt regarding the cause of this change, the importance of the fact can hardly be exaggerated.

\section{ON IDIOCY AND ITS RELATION TO TUBERCULOSIS.}

\section{BI J. LANGDON H. DOWN, M.D. LoND.;} PHYSICIAN TO THE TARLSWOOD ASTLUAT;

ASSISTANT-PHYSICLAN TO, AND TRCTURRR ON MATERIA MIEDICA AT, THE LONDON HOSPITAL,

The causes which have been assigned as productive of idiocy are numerous, and some have received special advocacy. Thus we are asked to belicve that one of the most profound misfortunes which afflicts our race-which to a great extent blots ont the characteristics of man, and approximates him to the lower animals-arises from sucking the thumb; and that if we could prevent a "fruitless sucking" idiocy would be immensely diminished, even if it did not cease to exist. Others, with wore show of reason, urge the intermarriage of blood relations as the prevailing cause; and so far does a belief in the potency of this latter element permeate society that I have been often gravely asked whether intermarriage of relations is not the cause of the idiocy of three-fourths of the cases which come under my observation. No one who has had an opportunity of investigating the influences which are at work in the production of congenital mental diseases can fail to be struck with the fact that they are, for the most part, to be traced to some inberent vice of constitution in the progenitors. He will discover in the parents elements of degeneracy which must have bad their share in producing the catastrophe. He will notice how by degrees the stock has deteriorated. He will be able to estimate how intemperance or sensuality leads slowly but surely to idiocy-how physical weakness of the parents culminates in the mental blight of the child.

Amongst the influences which have been regarded as connected with idiocy, very little attention has been given to that of tuberculosis, and $I$ ain not aware that any observations have been made with reference to the connexion of these two maladies.

Several writers have discussed the relations between insanity and tuberculosis, and have, I think, made it tolerably evident that there is more than an accidental connexion between them.

At the Earlswood Asylum, where the following observations have been made, the subjects of the inquiry are not likely to present an unfair proportion of tubercular idiots. Rather would they be likely to be below the arerage. The inmates are, for the most part, elected after great exertion, and the friends of a phthisical idiot would scarcely be likely to undertake the trouble for a manifestly short-lived child, even if the rules of the institution did not exclude it.

During the past eight years, from 1859 to 1866 inclusive, there have been 201 deaths. During this time there have been two epidemics of measles, one of scarlet fever, and two of whooping.cough, which have all added to the mortality. Moreover, a large proportion of the patients who succumbed to these epidemic diseases were those who would in all probability have eventually died of phthisis but for their interven. tion. Notwithstanding this circumstance there remains the fact, which my notes record, that, of the whole mortality, 39.8 is due to phthisis. To appreciate fully the meaning of these figures, it is necessary to consider the rate of mortality which rules amongst an idiot population. My notes show that, taking the last eight years, in some of which there were epidemics, while others were entirely free therefrom, the mortality presented an average of about 73.3 per 1000 ; whereas the mortality of the district in which the asylum is situated was about 18 per 1000 .

\begin{tabular}{|c|c|c|c|c|}
\hline Date. & $\begin{array}{c}\text { Average } \\
\text { popu- } \\
\text { lation. }\end{array}$ & $\begin{array}{c}\text { Gross } \\
\text { mortality. }\end{array}$ & $\begin{array}{l}\text { Deaths } \\
\text { from } \\
\text { phthisis. }\end{array}$ & $\longrightarrow$ \\
\hline 1859 & $285_{4}^{3}$ & 13 & 7 & \multirow{8}{*}{$\begin{array}{l}\text { Epidemic of typhoid. } \\
\text { Epidemic of measles. } \\
\text { Epidemic of measles and } \\
\text { scarlatina. }\end{array}$} \\
\hline 1860 & $308^{\frac{3}{4}}$ & 22 & 7 & \\
\hline 1861 & $318 \frac{1}{3}$ & 23 & 13 & \\
\hline 1862 & 322 & 33 & 8 & \\
\hline 1863 & $344 \frac{1}{2}$ & 47 & 15 & \\
\hline 1864 & 3695 & 19 & 10 & \\
\hline 1865 & $412 \frac{3}{4}$ & 13 & 9 & \\
\hline 1866 & $423 \frac{1}{2}$ & 31 & 11 & \\
\hline
\end{tabular}

The statistics of London show that the deaths from phthisis constitute 115 per 1000 of the general mortality. My notes of the causes of death at Earlswood indicate that phthisis was the actual cause of death in 398 per 1000 of the general mortality. The significance, however, of this, as before observed, can only be rightly estimated by recollecting that the general mortality is four times that of an ordinary community.

It will be obvious that, in consequence of the greater readiness with which idiots succumb to epidemic or other diseases, the proportional deaths from phthisis are thereby much decreased. This element may be fully brought out by dividing the eight years; bringing together the four epidemic years, and comparing them with the four non-epidemic years. It will then be seen that during the epidemic years 1860 , ' 62 , ' 63 , and ' 66 , the deaths from phthisis numbered 297 per 1000 of the general mortality, or considerably more than twice the ratio which rules in London; while in the non-epidemic years 1859 , ' 61 , ' 64 , and ' 65 , the deaths from phthisis reached the enormous proportion of 57058 per 1000 of the general mortality. I now propose to present a tabular view of the age and sex of those who died from phthisis.

\begin{tabular}{|c|c|c|c|c|c|}
\hline Age. & & Male. & & Female. & \\
\hline 7 & ...... & 1 & ...... & o & ....... \\
\hline 8 & ....... & 1 & ........ & 0 & ....... \\
\hline 9 & ....... & 1 & $\ldots \ldots$ & 2 & $\ldots \ldots$ \\
\hline 10 & ....... & 3 & ....... & 0 & $\ldots \ldots$ \\
\hline 11 & ........ & 2 & $\ldots \ldots$ & 1 & ....... \\
\hline 12 & ....... & 3 & $\ldots \ldots$ & 1 & $\ldots \ldots$ \\
\hline 13 & ...... & 6 & ...... & 2 & ...... \\
\hline 14 & ....... & 5 & ........ & 2 & $\ldots \ldots$ \\
\hline 15 & $\ldots \ldots$ & 1 & $\ldots \ldots$ & 0 & $\ldots \ldots$ \\
\hline 16 & ........ & 4 & ........ & 1 & $\ldots \ldots$ \\
\hline 17 & ....... & 2 & $\ldots \ldots$ & 6 & $\ldots \ldots$ \\
\hline 18 & ....... & 4 & $\ldots \ldots$ & 3 & ....... \\
\hline 19 & ....... & 8 & $\ldots \ldots$ & 1 & $\ldots \ldots$ \\
\hline 20 & ....... & 7 & ...... & 1 & $\ldots \ldots$ \\
\hline 21 & $\cdots$ & 6 & $\ldots \ldots$ & 2 & ....... \\
\hline 23 & ....... & 2 & $\ldots \ldots$ & 0 & $\ldots \ldots$ \\
\hline 27 & $\ldots$. & 1 & $\cdots \cdots$ & 0 & ....... \\
\hline 29 & ....... & 1 & $\ldots \ldots$ & 0 & $\ldots \ldots$ \\
\hline & & 58 & & 22 & \\
\hline
\end{tabular}

Dividing the ages into quinquennial periods, it will be observed that the greatest mortality from phthisis was from fifteen to twenty years of age. 